\section{M2A Wireless Capsule Endoscopy for Diagnosing Ulcerative Jejunoileitis Complicating Celiac Disease}

M2A wireless capsule endoscopy (Given Imaging, Ltd., Yoqneam, Israel) is an innovative diagnostic method that makes it possible to visualize the entire small bowel during normal peristalsis [1]. This new method appears to be superior to small-bowel radiography (enteroclysis or barium follow-through, or both) for evaluating small-bowel diseases [2,3]. However, its true diagnostic yield is still under evaluation. We describe here the case of a 76-year-old man with a 5-year history of celiac disease, who initially had complete clinical remission and histological improvement after switching to a glutenfree diet, but whose symptoms subsequently recurred despite strict adherence to dietary restrictions.

A barium follow-through showed dilation of the proximal small bowel, with loss of mucosal folds and segmentation of the barium contrast. M2A capsule endoscopy was then carried out and revealed multiple benign-appearing ulcers throughout the small bowel (Fig.1,2), with patchy mucosal inflammation. The patient did not report any use of nonsteroidal anti-inflammatory drugs, and there was no evidence of bowel ischemia. Enteroscopy was subsequently carried out, and histological examination of multiple biopsies throughout the proximal small bowel did not reveal T-cell monoclonality. A laparotomy with full-thickness biopsies of the

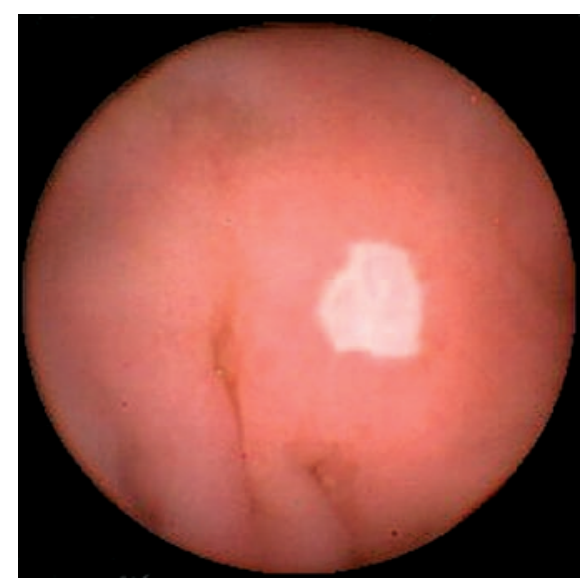

Figure 1 M2A capsule image of an ulcer in the proximal small bowel. small bowel was suggested in order to exclude malignancy, but the patient declined. Computed tomography of the abdomen was normal, and prednisolone $20 \mathrm{mg}$ daily was therefore administered, with iron and calcium supplements, to which the patient responded well. He is still receiving close clinical follow-up and has been in clinical remission for a period of 6 months.

Ulcerative jejunoileitis appears to be a rare complication of celiac disease [4]. However, in cases of refractory celiac disease, small-bowel radiology is often unhelpful [5] and enteroscopy is sometimes unavailable; the diagnosis often remains vague. This case highlights the usefulness of capsule endoscopy in diagnosing small-bowel diseases. The new method appears to be more helpful than classic small-bowel radiography. However, the inability to take biopsies during capsule endoscopy means that enteroscopy is still a necessary diagnostic tool.

\section{P. Apostolopoulos, G. Alexandrakis, E. Giannakoulopoulou, C. Kalantzis, I. S. Papanikolaou, C. Markoglou, N. Kalantzis \\ Dept. of Gastroenterology, Army Share Fund Hospital, Athens, Greece.}

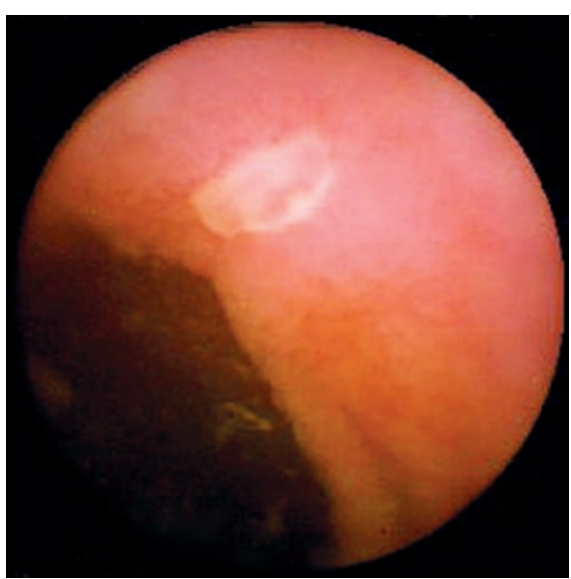

Figure 2 M2A capsule image of an ulcer in the distal small bowel.

\section{References}

${ }^{1}$ Iddan G, Meron G, Glukhovsky A, Swain P. Wireless capsule endoscopy. Nature 2000; 405: 417

${ }^{2}$ Costamagna G, Shah SK, Riccioni ME et al. A prospective trial comparing small bowel radiographs and video capsule endoscopy for suspected small bowel disease. Gastroenterology 2002; 123: 999- 1005

${ }^{3}$ Waye JD. Small-bowel endoscopy. Endoscopy 2003; 35: 15-21

${ }^{4}$ Ciclitira P. AGA technical review on celiac sprue. Gastroenterology 2001; 120: 1526 - 1540

${ }^{5}$ American Gastroenterology Association. Medical position statement: celiac sprue. Gastroenterology 2001; 120: $1522-1525$

\section{Corresponding Author}

\section{P. Apostolopoulos, M.D.}

Dept. of Gastroenterology

Army Share Fund Hospital

P.B. 155

19010 Kalivia

Greece

Fax: $\quad$ +30-229-107-1577

E-mail: periklisapo@yahoo.com 